\title{
10
}

\section{Desarrollar una empresa en el ámbito del patrimonio cultural inmaterial}

\section{Gaizka Aranguren Urroz}

Fundador y director general de Labrit

Patrimonio (https://labrit.net/es)

\section{Preparadas... - Contexto}

2003 no es una fecha mágica, París no es el punto de partida, ni la Convención de Salvaguarda del Patrimonio Cultural Inmaterial (PCI) es el hito fundacional a partir del cual se inicia la actividad en este ámbito de conocimiento, íntimamente ligado a la antropología, al folklore, las tradiciones, la oralidad... No obstante, es un hecho que la Convención UNESCO de París de 2003 es la referencia ineludible para la mayoría de las reflexiones que sobre el $\mathrm{PCl}$ se hacen en el mundo en la actualidad.

En 2006 España ratifica dicha convención y en 2009, quienes tuvimos oportunidad de estar en Teruel, firmamos una Carta que viene considerándose la semilla del Plan Nacional de Salvaguarda del Patrimonio Cultural Inmaterial.

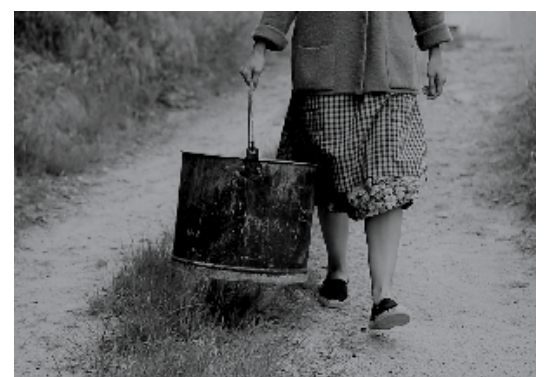

Las recreaciones de los testimonios recabados propicia la transmisión mediante la participación activa de las nuevas generaciones. Foto Labrit
Ya entonces, hace nueve años, llamaba la atención, por inusual, la presencia en Teruel de una empresa privada especializada en la gestión del PCl.

Es este un ámbito en el que el protagonismo ha correspondido a la academia (investigación) y a las administraciones públicas. A nadie en su sano juicio se le pasaba por la cabeza que la actividad en el ámbito del PCI pudiese autofinanciarse (incuso llegar a ser rentable), sin depender de subvenciones, ayudas o presupuestos públicos.

Listas... - Visión, misión y acción

Los referentes comunes del pasado, las vivencias, experiencias y saberes transmitidos, así como los proyectos de futuro compartido, componen el imaginario colectivo de cualquier grupo humano. Imaginario dinámico que cristaliza en su propia identidad.

Decodificando, analizando, categorizando y transmitiendo esos imaginarios fortalecemos la diversidad cultural mundial y promovemos el desarrollo local sostenible. Eso es gestionar el patrimonio inmaterial. Esa es la misión de Labrit en Europa y en todo el mundo.

La chispa que alumbró Labrit Patrimonio fue la necesidad de desarrollar una metodología sistematizada de recopilación de la memoria oral en formato audiovisual. Llevar la metodología antropológica, sin perder sus atributos científicos, a un grado de sistematización que posibilitase la recopilación, análisis, indexación y salvaguarda de historias de vida en cantidades superlativas. Es lo que hacemos, de la mano de la Universidad 
Pública de Navarra, en la Comunidad Foral, con el proyecto Navarchivo (Recopilación de las historias de vida del 1\% de la población de la Comunidad Foral de Navarra).

Conscientes de las dificultades que la transmisión oral intergeneracional tiene en la actualidad, desarrollamos una labor de transmisión también sistemática mediante todo tipo de canales de difusión y soportes: DVD, CD, libros, webs, teatro, unidades didácticas...

Por otra parte, la necesidad de las administraciones públicas de contar con profesionales expertas en el PCl para redactar planes directores, desarrollar preinventarios e inventarios, así como informes que permitan la elaboración de expedientes de declaración de bienes de interés cultural inmateriales, ha fortalecido nuestra labor de consultoría.

A todo ello se han unido los trabajos relacionados con la puesta en valor de este patrimonio para promover y fortalecer el desarrollo local. Las aplicaciones, siempre a instancias de las comunidades portadoras, de la gestión del $\mathrm{PCl}$ al ámbito del turismo cultural e identitario, a la revalorización de los productos con denominación de origen, artesanales e indicaciones geográficas protegidas, o a la generación de una imagen de marca local, se han convertido en algo cotidiano.

Todo, siempre, de la mano de las comunidades. No para ellas, que también, sino fundamentalmente con ellas.

\section{"La chispa que alumbró} Labrit Patrimonio fue la necesidad de desarrollar una metodología sistematizada de recopilación de la memoria oral en formato audiovisual"

\section{¡Ya! - Desarrollo y mirada larga}

Labrit Patrimonio es hoy una estructura empresarial dedicada a innovar e investigar sobre los beneficios que la gestión del patrimonio cultural inmaterial puede reportar a partir de su aplicación en diversos ámbitos productivos; turismo cultural/identitario y economía productiva ligada al entorno natural y cultural, y memoria personal y familiar fundamentalmente.

Un equipo con capacitación multidisciplinar en el que se suman esfuerzos profesionales del ámbito de la antropología, la comunicación, la publicidad, el diseño y la producción audiovisual, todos ellos con un profundo conocimiento del contexto cultural y legal en el que deben desenvolverse.

Tras nueve años de experiencia, se ha asentado un proyecto empresarial que busca nuevas vías de aplicación a los contenidos inmateriales con los que trabaja. Así, el desarrollo local está hoy íntimamente ligado a una imagen de "marca" cuyos valores supremos descansan, precisamente, en los elementos y referentes que constituyen su propio imaginario colectivo, su ecosistema cultural. Es precisamente en la identificación de dichos elementos y en la gestión de los mismos en beneficio de sus portadores donde encontramos nuevas palancas de valorización de los servicios y productos locales.

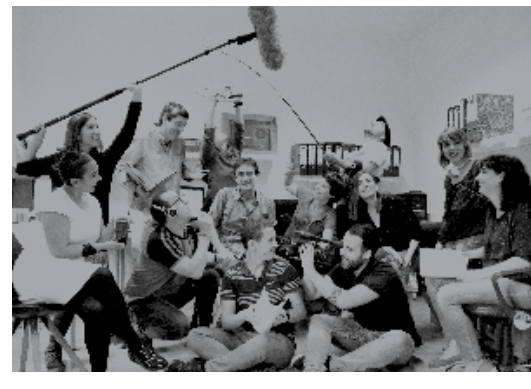

Un equipo multidisciplinar de quince personas, con base en Pamplona y delegaciones en Madrid y Buenos Aires, componen Labrit en la actualidad. Foto Labrit 


\section{"Tras nueve años de experiencia, se ha asentado un proyecto empresarial que busca nuevas vías de aplicación a los contenidos inmateriales con los que trabaja"}

En la actualidad Labrit Patrimonio cuenta con un plantilla de quince personas, con sede central en Pamplona y delegaciones en Madrid y Buenos Aires.

Nuestra experiencia no alcanza a los 25 años de la revista $\mathrm{PH}$, pero entendemos que nuestros nueve años de trabajo en la gestión del PCI desde una estructura empresarial son una muestra significativa de la evolución de la actividad en este ámbito.

\section{Futuro prometedor}

Vemos un futuro luminoso. Entendemos que la gestión comunicativa del patrimonio cultural inmaterial en beneficio del desarrollo de zonas rurales desfavorecidas y de ámbitos urbanos va a normalizarse en la medida en que los resultados sean conocidos.

A todas las estructuras, públicas y privadas, que trabajamos en el ámbito del $\mathrm{PCl}$, nos ha tocado y todavía nos sigue tocando abrir camino explicando los conceptos y elementos con los que trabajamos desde el principio. Una vez y otra. No obstante, observamos que términos como inmaterial, memoria, patrimonio, oralidad, imaginario... son cada vez más utilizados y publicados.

Precisamente eso es lo que nos gustaría que siguiese haciendo la revista $\mathrm{PH}$. Que siga regando el campo. Un campo que cada vez sentimos más abonado para las iniciativas en el ámbito del PCl.

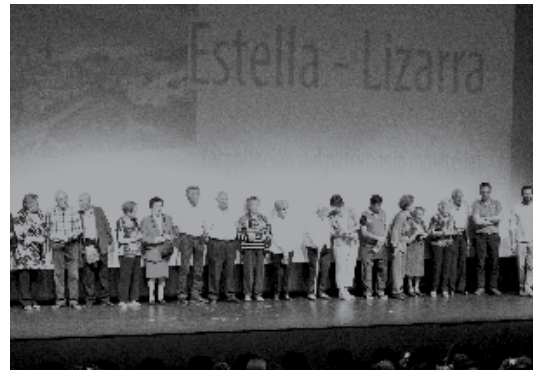

Presentación en Estella-Lizarra (Navarra). Foto Labrit
He aquí algunos ejemplos del trabajo de Labrit

Recopilación de la memoria oral: https://vimeo.com/255930162

Transmisión de contenidos: https://vimeo.com/215006489

Consultoría para las administraciones públicas:

https://www.navarra.es/NR/ rdonlyres/D9B1D037-9996-46CAA3F2-319786EDD8EE/360005/ tecnologianavarraparagestionpatrimonio culturalinma.pdf

Aplicación al ámbito turístico: https://vimeo.com/66565091

Aplicación al ámbito productivo: https://vimeo.com/142548458

Extensión de la metodología al ámbito privado. Gestión del patrimonio familiar inmaterial:

https://labrit.net/es/patrimonio-familiar/ 